www.nature.com/pj

\title{
Synthesis of a conjugated copolymer with benzodithiophene and benzimidazole units
}

\author{
Suhee Song ${ }^{1}$, Seo-Jin $\mathrm{Ko}^{2}$, Ju Ae Kim${ }^{1}$, Youngeup $\mathrm{Jin}^{3}$, Il Kim ${ }^{4}$, Jin Young Kim² and Hongsuk Suh${ }^{1}$ \\ A new accepter unit, dimethyl-2 $\mathrm{H}$-benzimidazole, was prepared and utilized for the synthesis of conjugated polymers \\ containing an electron donor-acceptor pair for organic photovoltaics (OPVs). A dimethyl-2 $\mathrm{H}$-benzimidazole unit was designed \\ to replace the benzothiadiazole (BT) unit of PCDTBT. An advantage of dimethyl-2 $\mathrm{H}$-benzimidazole compared with the BT moiety \\ of PCDTBT is that the solubility of the polymer is improved while the 1,2-quinoid form is maintained to lead the coplanarity \\ of the backbone. New semiconducting copolymers with dialkoxybenzo[1,2-b:3,4-b']dithiophene as the electron-rich unit and \\ 2,2-dimethyl-4,7-di(2-thienyl)-2 $\mathrm{H}$-benzimidazole as the electron-deficient unit were synthesized by $\mathrm{Pd}(0)$-catalyzed Stille coupling \\ polymerization. The resulting P2:PC71BM device had a open circuit voltage $\left(V_{0 C}\right)$ value of $0.65 \mathrm{~V}$, a short circuit current density \\ $\left(J_{\mathrm{SC}}\right)$ value of $1.86 \mathrm{mAcm}^{-2}$ and a FF value of 0.39 , with a final power conversion efficiency (PCE) value of $0.47 \%$. \\ Polymer Journal (2013) 45, 555-559; doi:10.1038/pj.2012.168; published online 19 September 2012
}

Keywords: photovoltaics; polymer; synthesis; $2 \mathrm{H}$-benzimidazole

\section{INTRODUCTION}

Tremendous research efforts have been focused on all-solution processed organic photovoltaics (OPVs) with bulk heterojunction architectures to realize low-cost manufacturing, 1,2 including techniques such as ink-jet printing, ${ }^{3}$ brush painting ${ }^{4}$ and roll-to-roll processing. ${ }^{5,6}$ To achieve highly efficient OPVs, the most critical challenge at the molecular level is to develop low-bandgap-conjugated polymers with sufficient solubility for solution processability and high hole mobility for efficient charge transport. ${ }^{1,7}$ The interaction between the electron-rich and electron-deficient segments along the conjugated polymer backbone can effectively reduce the bandgaps $\left(E_{\mathrm{g}}<1.8 \mathrm{eV}\right)$ of the polymers in bulk heterojunction solar cells. ${ }^{1,8-11}$

Many of the low-bandgap (1.4-1.9 eV)-conjugated polymers with excellent efficiencies have electron-deficient heterocycles, such as benzothiadiazole $(\mathrm{BT})^{12}$ or benzimidazole, ${ }^{13,14}$ and electron-rich moieties, such as carbazole, ${ }^{15,16}$ fluorene, ${ }^{17}$ cyclopentaphenanthrene ${ }^{18}$ or thiophene. ${ }^{19}$ The dialkoxybenzo[1,2-b:3,4- $\left.b^{\prime}\right]$ dithiophene unit has emerged as a promising electron-rich unit in conjugated polymers for OPVs and thin-film transistors to provide power conversion efficiencies $>7 \%{ }^{20}$ In the dimethyl-2H-benzimidazole unit, the sulfur at the 2 position of the BT moiety is replaced with dialkyl substituted carbon while the 1,2-quinoid form is maintained, resulting in a highly soluble electron-deficient moiety for the efficient intramolecular charge transfer (ICT) to generate polymers with low bandgaps. ${ }^{13,14}$ Polymers with an dimethyl- $2 \mathrm{H}$-benzimidazole unit absorb at a longer wavelength compared with those containing the same electron-rich and BT units. To achieve absorption at longer wavelengths, two thiophene units without alkyl groups can be incorporated between the electron-rich and electron-deficient units, resulting in low solubility of the polymers. ${ }^{21}$

In this study, we report new conjugated copolymers, poly (2,6-(4,8-dioctyloxybenzo[1,2-b:3,4- $\left.b^{\prime}\right]$ dithiophene)-alt-5,5-(4',7'-di-2thienyl-2,2-dimethyl-2H-benzimidazole); P1) and poly(2,6-(4,8-bis (2-ethylhexyloxy)benzo[1,2-b:4,5- $\left.b^{\prime}\right]$ dithiophene)-alt-5,5-(4', $7^{\prime}$-di-2-thienyl2,2-dimethyl-2H-benzimidazole); P2), containing a new type of electron-deficient dimethyl-2H-benzimidazole unit and electron-rich unit, dialkoxybenzo[ $\left.1,2-b: 3,4-b^{\prime}\right]$ dithiophene, to obtain absorption at longer wavelengths for OPVs. The photovoltaic properties of the polymers were investigated by fabricating polymer solar cells with the configuration of ITO/PEDOT:PSS/polymer:PCBM/Al.

\section{EXPERIMENTAL PROCEDURE}

\section{General}

All reagents were purchased from Aldrich (St Louis, MO, USA) or TCI (Tokyo, Japan) and were used without further purification. Solvents were purified by normal procedures and were handled under a moisture-free atmosphere. ${ }^{1} \mathrm{H}$ and ${ }^{13} \mathrm{C}$ nuclear magnetic resonance (NMR) spectra were recorded with a Varian Gemini-300 (300 MHz) (Palo Alto, CA, USA) spectrometer, and chemical shifts were recorded in units of p.p.m. with tetramethyl silane (TMS) as the internal standard. Flash column chromatography was performed with Merck silica gel 60 (Merck, Whitehouse, KY, USA) (particle size 230-400 mesh

\footnotetext{
${ }^{1}$ Department of Chemistry and Chemistry Institute for Functional Materials, Pusan National University, Busan, Korea; ${ }^{2}$ Interdisciplinary School of Green Energy, Ulsan National Institute of Science and Technology, Ulsan, Korea; ${ }^{3}$ Department of Industrial Chemistry, Pukyong National University, Busan, Korea and ${ }^{4}$ The WCU Center for Synthetic Polymer Bioconjugate Hybrid Materials, Department of Polymer Science and Engineering, Pusan National University, Busan, Korea

Correspondence: Dr JY Kim, Interdisciplinary School of Green Energy, Ulsan National Institute of Science and Technology, Ulsan 689-798, Korea.

E-mail: yjkim@unist.ac.kr

or Dr H Suh, Department of Chemistry and Chemistry Institute for Functional Materials, Pusan National University, Busan 609-735, Korea.

E-mail: hssuh@pusan.ac.kr
}

Received 20 April 2012; revised 17 July 2012; accepted 17 July 2012; published online 19 September 2012 
American Society for Testing Materials (ASTM)) with ethyl acetate/hexane or methanol/methylene chloride gradients unless otherwise indicated. Analytical thin layer chromatography was conducted using Merck $0.25-\mathrm{mm}$ silica gel $60 \mathrm{~F}$ pre-coated aluminum (Al) plates with fluorescence indicator UV254. Highresolution mass spectra (HRMS) were recorded on a JEOL JMS-700 mass spectrometer (JEOL, Tokyo, Japan) under electron impact (EI) conditions at the Korea Basic Science Institute (Daegu, South Korea). The molecular weight $\left(M_{\mathrm{w}}\right)$ and polydispersity of the polymers were determined by gel permeation chromatography analysis with a polystyrene standard calibration. Ultraviolet-visible absorption spectra were recorded by a Varian 5E UV/VIS/ NIR spectrophotometer (Varian, Palo Alto, CA, USA), while an Oriel InstaSpec IV CCD detection system (Oriel, Irvine, CA, USA) with a xenon lamp was used for electroluminescence spectrum measurements.

Solar cells were fabricated on an indium tin oxide (ITO)-coated glass substrate with the following structure: ITO-coated glass substrate/poly(3,4-ethylenedioxythiophene)(PEDOT:PSS)/polymer: $\mathrm{PC}_{71} \mathrm{BM} / \mathrm{Al}$. The ITO-coated glass substrate was cleaned with detergent, ultrasonicated in acetone and isopropyl alcohol, and subsequently dried overnight in an oven. PEDOT:PSS (Baytron PH, Bayer, Germany) was spin-cast from aqueous solution to form a 40-nm-thick film. The substrate was dried for $10 \mathrm{~min}$ at $140{ }^{\circ} \mathrm{C}$ in air and then transferred to a glove box to spin-cast the charge separation layer. A solution containing a mixture of polymer: $\mathrm{PC}_{71} \mathrm{BM}$ in chlorobenzene solvent with a concentration of $7 \mathrm{wt} \mathrm{ml}^{-1} \%$ was then spin-cast on top of the PEDOT/PSS layer. The film was dried for $60 \mathrm{~min}$ at $70^{\circ} \mathrm{C}$ in the glove box. The sample was heated at $80^{\circ} \mathrm{C}$ for $10 \mathrm{~min}$ in air. Then, an $\mathrm{Al}(100 \mathrm{~nm})$ electrode was deposited by thermal evaporation in a vacuum of $\sim 5 \times 10^{-7}$ Torr. The current density-voltage $(J-V)$ characteristics of the devices were measured using a Keithley 236 Source Measure Unit (Keithley, Cleveland, OH, USA). Solar cell performance was measured using an Air Mass 1.5 Global (AM 1.5 G) solar simulator with an irradiation intensity of $1000 \mathrm{Wm}^{-2}$. An aperture $\left(12.7 \mathrm{~mm}^{2}\right)$ was used on top of the cell to eliminate extrinsic effects such as cross-talk, waveguiding, shadow effects, and so on. The spectral mismatch factor was calculated by comparing the solar simulator spectrum with the AM 1.5 spectrum at room temperature.

\section{Synthesis of 4,7-dibromo-2,2-dimethyl-2H-benzimidazole (3)}

A stirred solution of 3,6-dibromobenzene-1,2-diamine (1; 10 g, $37.65 \mathrm{mmol})$, acetone $(2 ; 10 \mathrm{ml})$ and acetic acid $(10 \mathrm{ml})$ in diethyl ether $(200 \mathrm{ml})$ was heated at $50{ }^{\circ} \mathrm{C}$ overnight. After the reaction mixture was cooled to room temperature, water and ethyl acetate were added. The aqueous phase was extracted with ethyl acetate, and combined organic layers were dried over $\mathrm{MgSO}_{4}$. The solvent was removed under vacuum, and the residue was purified by column chromatography to give 4,7-dibromo-2,2-dimethyl-2,3-dihydro- $1 \mathrm{H}$-benzimidazole. $\mathrm{MnO}_{2}(7.4 \mathrm{~g}, 85 \mathrm{mmol})$ was added to a stirred solution of 4,7-dibromo-2,2-dimethyl-2,3-dihydro- $1 \mathrm{H}$ benzimidazole in $50 \mathrm{ml}$ of tetrahydrofuran (THF) at room temperature. ${ }^{14} \mathrm{After} 3 \mathrm{~h}$, the solid was filtered and washed with THF. The combined organic phase was concentrated under reduced pressure and purified by flash column chromatography to yield $3.2 \mathrm{~g}(28 \%)$ of compound 3 as a yellow powder. Melting point (m.p.) $132^{\circ} \mathrm{C} ;{ }^{1} \mathrm{H}$ NMR $\left(300 \mathrm{MHz}\right.$, acetone-d $\left.{ }_{6}\right): \delta$ (p.p.m.) $1.52(\mathrm{~s}, 6 \mathrm{H}), 6.49$ (s, 2H); ${ }^{13} \mathrm{C}$ NMR (75 MHz, acetone- $\mathrm{d}_{6}$ ): $\delta$ (p.p.m.) 79.66, 98.31, 121.74, 121.80, 139.68. $\operatorname{HRMS}\left(m / z, \mathrm{EI}^{+}\right)$calcd for $\mathrm{C}_{9} \mathrm{H}_{8} \mathrm{~N}_{2} \mathrm{Br}_{2}$ 301.9054, found 301.9056 .

Synthesis of 2,2-dimethyl-4,7-di(2-thienyl)-2H-benzimidazole (4) Dichlorobis(triphenylphosphine)palladium(II; $2 \mathrm{~mol} \%$ ) was added to a stirred solution of 4,7-dibromo-2,2-dimethyl- $2 \mathrm{H}$-benzimidazole $(3 ; 2.7 \mathrm{~g}, 8.9 \mathrm{mmol})$ and tributyl(2-thienyl)stannane ( $16.6 \mathrm{~g}, 44.4 \mathrm{mmol})$ in $40 \mathrm{ml}$ of THF at room temperature. The reaction mixture was stirred for $12 \mathrm{~h}$ at $80^{\circ} \mathrm{C}$, concentrated under reduced pressure and purified by flash column chromatography to yield $1.4 \mathrm{~g}$ (51\%) of compound 4 as a red solid. M.p. $172{ }^{\circ} \mathrm{C} ;{ }^{1} \mathrm{H}$ NMR $\left(300 \mathrm{MHz}, \mathrm{CDCl}_{3}\right)$ : $\delta$ (p.p.m.) 1.67 (s, 6H), 7.13 (d of d, $2 \mathrm{H}, J=3.9$ and $5.4 \mathrm{~Hz}$ ), $7.30(\mathrm{~s}, 2 \mathrm{H}), 7.38$ (d of d, $2 \mathrm{H} . J=1.1$ and $4.9 \mathrm{~Hz}$ ), $8.03\left(\mathrm{~d}\right.$ of d, $2 \mathrm{H}, J=1.1$ and $3.5 \mathrm{~Hz}$ ); ${ }^{13} \mathrm{C}$ NMR $\left(75 \mathrm{MHz}, \mathrm{CDCl}_{3}\right.$ ): $\delta$ (p.p.m.) 22.38, 105.40, 126.85, 128.24, 128.28, 128.80, 128.99, 138.94, 157.94. $\operatorname{HRMS}\left(\mathrm{m} / \mathrm{z}, \mathrm{EI}^{+}\right)$calcd for $\mathrm{C}_{17} \mathrm{H}_{14} \mathrm{~N}_{2} \mathrm{~S}_{2} 310.0598$, found 310.0600

\section{Synthesis of 4,7-bis(5-bromo-2-thienyl)-2,2-dimethyl-2H-} benzimidazole (5)

$N$-bromosuccinimide $(1.52 \mathrm{~g}, 8.6 \mathrm{mmol})$ was added to a stirred solution of 2,2-dimethyl-4,7-di(2-thienyl)-2H-benzimidazole (4; $1.3 \mathrm{~g}, 4.19 \mathrm{mmol}$ ) in THF at room temperature. After $3 \mathrm{~h}$ at room temperature, water and ethyl acetate were added. The organic layer was washed with $3 \times 100 \mathrm{ml}$ of water. The organic phase was concentrated under reduced pressure and purified by flash column chromatography to yield $1.25 \mathrm{~g}(64 \%)$ of compound 5 as a red solid. M.p. $207{ }^{\circ} \mathrm{C} ;{ }^{1} \mathrm{H}$ NMR $\left(300 \mathrm{MHz}, \mathrm{CDCl}_{3}\right): \delta$ (p.p.m.) 1.58 (s, $\left.6 \mathrm{H}\right), 7.08$ (d, $2 \mathrm{H}$ $J=3.9 \mathrm{~Hz}), 7.21(\mathrm{~s}, 2 \mathrm{H}), 7.69(\mathrm{~d}, 2 \mathrm{H}, J=3.9 \mathrm{~Hz}) ;{ }^{13} \mathrm{C} \mathrm{NMR}\left(75 \mathrm{MHz}, \mathrm{CDCl}_{3}\right)$ : $\delta$ (p.p.m.) 22.02, 105.59, 115.11, 127.56, 127.90, 128.08, 130.72, 139.86, 157.45 . $\operatorname{HRMS}\left(m / z, \mathrm{EI}^{+}\right)$calcd for $\mathrm{C}_{17} \mathrm{H}_{12} \mathrm{Br}_{2} \mathrm{~N}_{2} \mathrm{~S}_{2} 465.8809$, found 465.8810 .

Synthesis of poly(2,6-(4,8-dioctyloxybenzo[1,2-b:3,4- $\left.b^{\prime}\right]$ dithiophene)alt-5,5-( $4^{\prime}, 7^{\prime}$-di-2-thienyl-2,2-dimethyl-2H-benzimidazole); P1)

Carefully purified 2,6-bis(trimethyltin)-4,8-dioctyloxybenzo[1,2-b:3,4- $\left.b^{\prime}\right]$ dithiophene $(\mathbf{6})^{20}$ (1 eq), 4,7-bis(5-bromo-2-thienyl)-2,2-dimethyl-2H-benzimidazole (5), $\mathrm{P}(o \text {-tolyl })_{3}(1 \mathrm{eq})$ and $\mathrm{Pd}_{2}(\mathrm{dba})_{3}(3 \mathrm{~mol} \%)$ were dissolved in $10 \mathrm{ml}$ of toluene. The mixture was refluxed with vigorous stirring for 2 days under an argon atmosphere. After cooling to room temperature, the mixture was poured into methanol. The precipitated material was recovered by filtration. The resulting solid material was reprecipitated using $100 \mathrm{ml}$ of THF/1.01 of methanol several times to remove the residual catalyst. The yield of the polymerization reaction was $\sim 35 \%$. The resulting polymer was soluble in THF, $\mathrm{CHCl}_{3}, o$-dichlorobenzene (ODCB) and toluene.

Synthesis of poly(2,6-(4,8-bis(2-ethylhexyloxy)benzo[1,2-b:4,5- $\left.b^{\prime}\right]$ dithiophene)-alt-5,5-(4',7'-di-2-thienyl-2,2-dimethyl-2Hbenzimidazole); P2)

This dark purple copolymer was prepared by a procedure similar to that for $\mathbf{P 1}$, using 2,6-bis(trimethyltin)-4,8-bis(2-ethylhexyloxy)benzo[1,2-b:4,5- $\left.b^{\prime}\right]$ dithiophene $(7)^{21}$ (1 eq) and 4,7-bis(5-bromo-2-thienyl)-2,2-dimethyl-2H-benzimidazole $(5 ; 1 \mathrm{eq})$ as the monomers. The yield of the polymerization reaction was $\sim 60 \%$.

\section{RESULTS AND DISCUSSION}

\section{Synthesis and characterization}

The general synthesis routes followed to produce the monomers and polymers are outlined in Scheme 1. In the first step, 3,6-dibromobenzene-1,2-diamine (1) was treated with acetone and acetic acid followed by $\mathrm{MnO}_{2}$ to generate 2,2-dimethyl-2H-benzimidazole (3) which was coupled with tributyl(2-thienyl)stannane by using dichlorobis(triphenylphosphine)palladium (II) to produce 2,2-dimethyl-4,7di(2-thienyl)-2H-benzimidazole (4). Compound 4 was brominated by $\mathrm{N}$-bromosuccinimide to provide monomer 4,7-bis(5-bromo2-thienyl)-2,2-dimethyl-2H-benzimidazole (5). Compound 5, as an electron-accepting moiety, and 2,6-bis(trimethyltin)-4,8-dioctyloxybenzo[1,2-b:3,4- $\left.b^{\prime}\right]$ dithiophene $(6)^{22}$ and 2,6-bis(trimethyltin)-4,8-bis (2-ethylhexyloxy)benzo[1,2- $\left.b: 4,5-b^{\prime}\right]$ dithiophene $(7),{ }^{23}$ as electrondonating units, were co-polymerized through the Stille coupling reaction with a $\mathrm{Pd}(0)$ catalyst to yield $\mathbf{P} 1$ and $\mathbf{P} 2$. The structures and purities of the monomers were confirmed by ${ }^{1} \mathrm{H}-\mathrm{NMR},{ }^{13} \mathrm{C}-\mathrm{NMR}$ and HRMS. Supplementary information shows the H-NMR, C-NMR and mass spectra of the synthesized compounds. The synthesized polymers were soluble in various organic solvents such as chloroform, chlorobenzene, THF, dichloromethane and ODCB. The synthesized polymers have a lower $M_{\mathrm{w}}$ owing to their low solubility. Table 1 summarizes the polymerization results, including the $M_{\mathrm{w}}$, polydispersity index and thermal stability of the polymers. Weight-averaged $M_{\mathrm{w}}$ of 4300 and 9300 and polydispersity indexes (polydispersity index, $M_{\mathrm{w}} / M_{\mathrm{n}}$ ) of 1.4 and 6.7 for $\mathbf{P 1}$ and $\mathbf{P} 2$ were determined by gel permeation chromatography, respectively.

The thermal properties of the polymers were characterized by thermal gravimetric analysis, as shown in Figure 1. Thermal gravimetric analysis was performed with a thermal gravimetric analysis 2950 apparatus in a nitrogen atmosphere at a heating rate of $10^{\circ} \mathrm{C} \mathrm{min}^{-1}$ to $600^{\circ} \mathrm{C}$. Differential scanning calorimetry analysis was performed under a nitrogen 


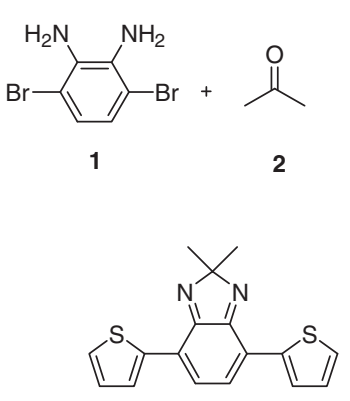

4

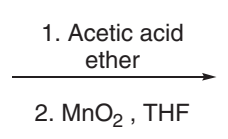

2. $\mathrm{MnO}_{2}, \mathrm{THF}$

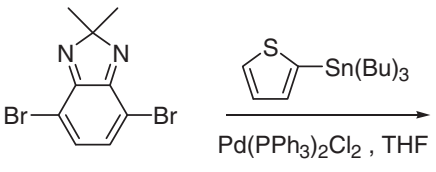

3

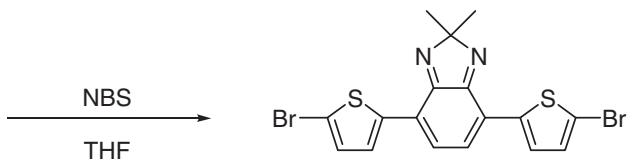

5
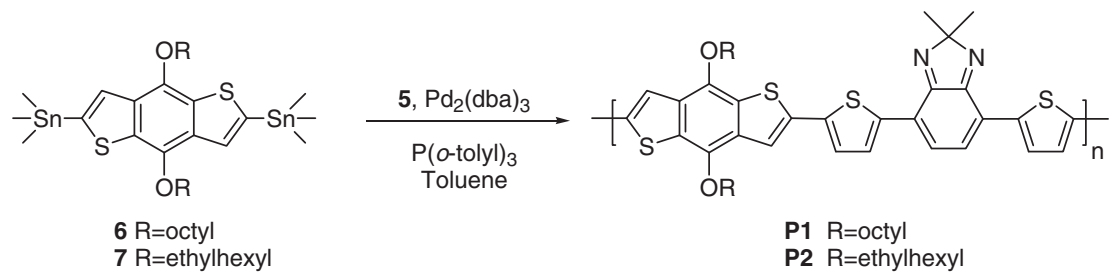

Scheme 1 Synthetic route for synthesis of the monomer and polymers.

Table 1 Polymerization results and thermal properties of polymers

\begin{tabular}{lllll}
\hline Polymer & $\mathrm{M}_{n}{ }^{\mathrm{a}}$ & $\mathrm{M}_{w}{ }^{\mathrm{a}}$ & $P D l^{\mathrm{a}}$ & $T G A\left(\mathrm{~T}_{d}\right)^{\mathrm{b}}$ \\
\hline P1 & 2900 & 4300 & 1.4 & 328 \\
P2 & 1400 & 9300 & 6.7 & 336 \\
\hline
\end{tabular}

Abbreviations: GPC, gel permeation chromatography; $M_{\mathrm{w}}$, molecular weight; PDI, polydispersity index; TGA, thermal gravimetric analysis; THF, tetrahydrofuran.

${ }^{\mathrm{a}} M_{\mathrm{w}}$ and PDI of the polymers were determined by GPC in THF using polystyrene standards.

bonset decomposition temperature ( $5 \%$ weight loss) measured by TGA under $\mathrm{N}_{2}$.

atmosphere $\left(50 \mathrm{ml} \mathrm{min}^{-1}\right)$ on a DSC 2920 (New Castle, DE, USA) apparatus at a heating rate of $10^{\circ} \mathrm{Cmin}^{-1}$. Thermal gravimetric analysis showed that $\mathbf{P} 1$ and $\mathbf{P} 2$ are thermally stable with only $\sim 5 \%$ weight loss at $328^{\circ} \mathrm{C}$ and $336^{\circ} \mathrm{C}$, respectively. High thermal stability is required to prevent the degradation of polymers in photovoltaic devices upon annealing. ${ }^{24}$ The high thermal stability of the resulting polymers prevents the deformation of polymer morphology and is important for OPV applications.

\section{Optical properties}

The optical properties of the polymers were investigated both in chloroform solution and as thin films. The absorption data for the polymers are shown in Figure 2 and summarized in Table 2. Uniform polymer films were prepared on quartz plates by spin-casting their ODCB solutions at room temperature. The absorption spectra of P1 and P2 exhibited maximum peaks at $\sim 386,576$ and $438,598 \mathrm{~nm}$ in solution, respectively. The absorption spectrum of $\mathbf{P} \mathbf{2}$ was redshifted as compared with that of P1 due to its higher $M_{\mathrm{W}}$ in comparison with P1. The solid films of P1 and P2 showed absorption bands with maximum peaks at $\sim 449,633$ and 434, $636 \mathrm{~nm}$ and absorption onsets at 799 and $810 \mathrm{~nm}$, corresponding to bandgaps of 1.55 and $1.53 \mathrm{eV}$, respectively. The absorption at the shorter wavelength for $\mathbf{P} 2$ in the solid state was blueshifted by $\sim 15 \mathrm{~nm}$ as compared with P1 due to its bulky ethylhexyl side chain.

\section{Electrochemical properties}

The electrochemical properties of the polymer were determined from the bandgap, as estimated from the absorption onset wavelength, and the highest occupied molecular orbital (HOMO) energy level, which was estimated by cyclic voltammetry. Cyclic voltammetry

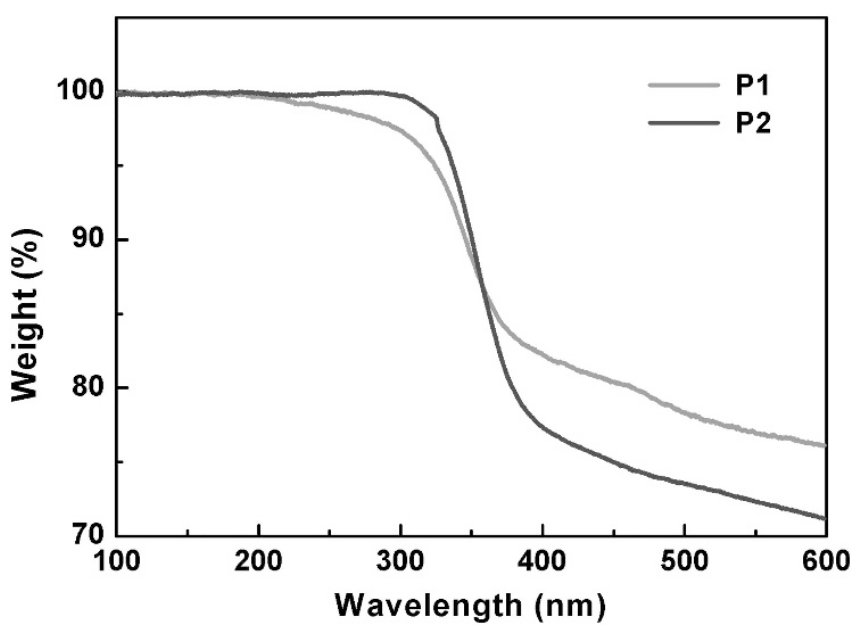

Figure 1 Thermogravimetric analysis of the polymers under N2. A full color version of this figure is available at Polymer Journal online.

was performed in a solution of tetrabutylammonium tetrafluoroborate $(0.10 \mathrm{M})$ in acetonitrile at a scan rate of $100 \mathrm{mV} \mathrm{s}^{-1}$ at room temperature under an argon atmosphere. A platinum electrode $\left(\sim 0.05 \mathrm{~cm}^{2}\right)$ coated with a thin polymer film was used as the working electrode. A Pt wire and an $\mathrm{Ag} / \mathrm{AgNO}_{3}$ electrode were used as the counter electrode and reference electrode, respectively. The energy level of the $\mathrm{Ag} / \mathrm{AgNO}_{3}$ reference electrode (calibrated by an $\mathrm{Fc} / \mathrm{Fc}^{+}$ redox system) was $4.8 \mathrm{eV}$ below the vacuum level. ${ }^{25}$ The cyclic voltammetry spectra are shown in Figure 3 , and the oxidation potentials derived from the onsets of electrochemical p-doping are summarized in Table 3. The HOMO and lowest unoccupied molecular orbital levels were calculated according to the empirical formulas $E_{\mathrm{HOMO}}=-\left(\left[E_{\text {onset }}\right]^{\text {ox }}+4.8\right) \mathrm{eV}$ and $E_{\mathrm{LUMO}}=$ $-\left(\left[E_{\text {onset }}\right]^{\text {red }}+4.8\right)$ eV, respectively. The $\mathbf{P} \mathbf{1}$ and $\mathbf{P} 2$ polymers exhibited absorption onset wavelengths of 799 and $810 \mathrm{~nm}$ as solid thin films, which correspond to bandgaps of 1.55 and $1.53 \mathrm{eV}$, respectively. The polymers exhibited irreversible processes in the oxidation scan. The oxidation onsets of $\mathbf{P} \mathbf{1}$ and $\mathbf{P} 2$ were estimated to be 0.59 and 

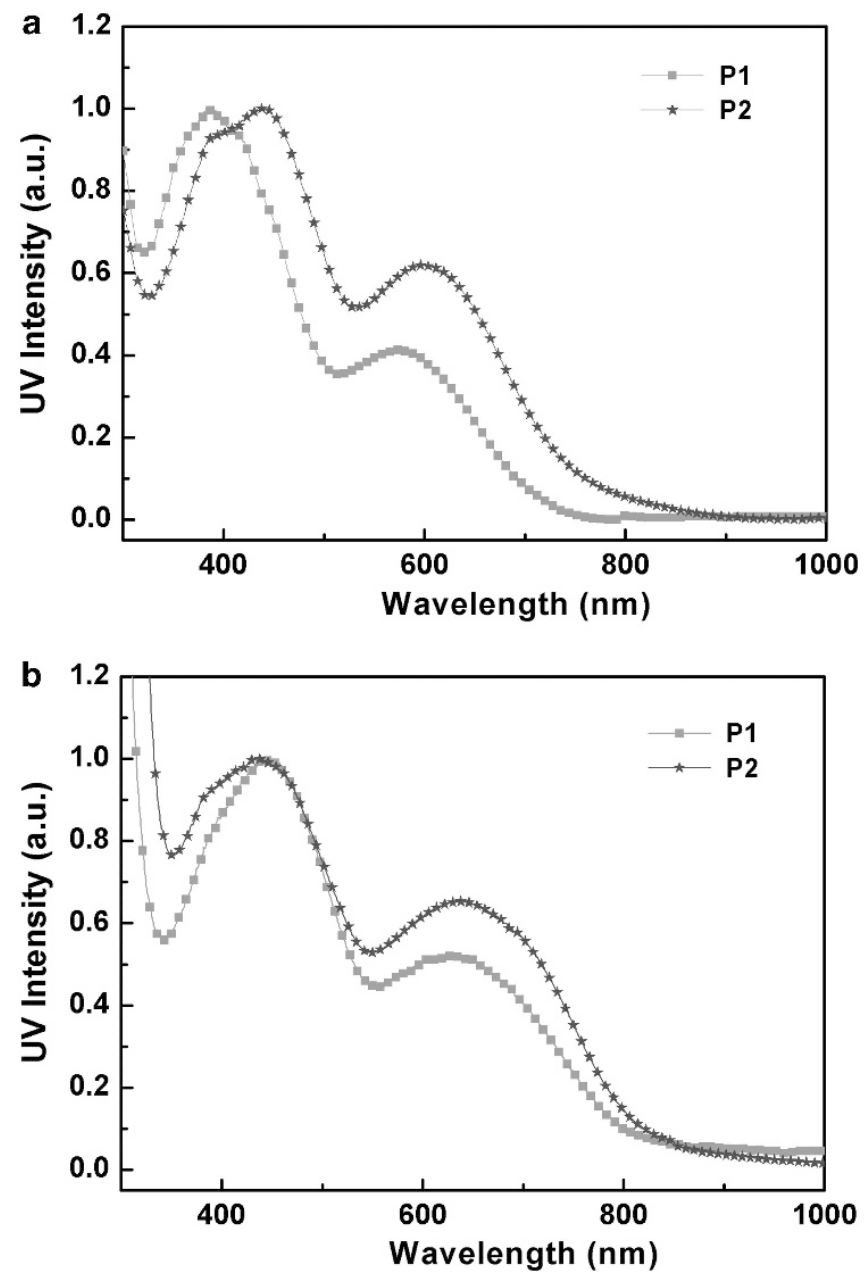

Figure 2 Ultraviolet (UV)-visible absorption spectra of polymers in chloroform solution (a) and in the solid state (b). A full color version of this figure is available at Polymer Journal online.

Table 2 Characteristics of the UV-vis absorption spectra

\begin{tabular}{lcc}
\hline Polymer & In solution & In thin film \\
\hline P1 & 386576 & 449633 \\
P2 & 438598 & 434636 \\
\hline
\end{tabular}

Abbreviations: UV, ultraviolet; vis, visible.

$0.56 \mathrm{~V}$, corresponding to HOMO energy levels of -5.39 and $-5.37 \mathrm{eV}$, respectively. The reduction potential onsets of $\mathbf{P} \mathbf{1}$ and $\mathbf{P} 2$ were -1.24 and $-1.20 \mathrm{~V}$, which correspond to lowest unoccupied molecular orbita energy levels of -3.56 and $-3.60 \mathrm{eV}$, respectively. The electrochemical bandgaps, as calculated from the cyclic voltammetry data, were $\sim 1.83$ and $1.76 \mathrm{eV}$, somewhat higher than the optical bandgaps estimated from the onset wavelengths of the absorption spectra.

\section{Polymer photovoltaic properties}

The OPVs were fabricated by spin-casting the ODCB solutions of $\mathrm{PC}_{61} \mathrm{BM} /$ polymers. All polymers were applied as donors in a conventional bulk heterojunction-type OPV device with $\mathrm{PC}_{61} \mathrm{BM}$ as the acceptor, which has been widely used for this purpose. Typical $J-V$

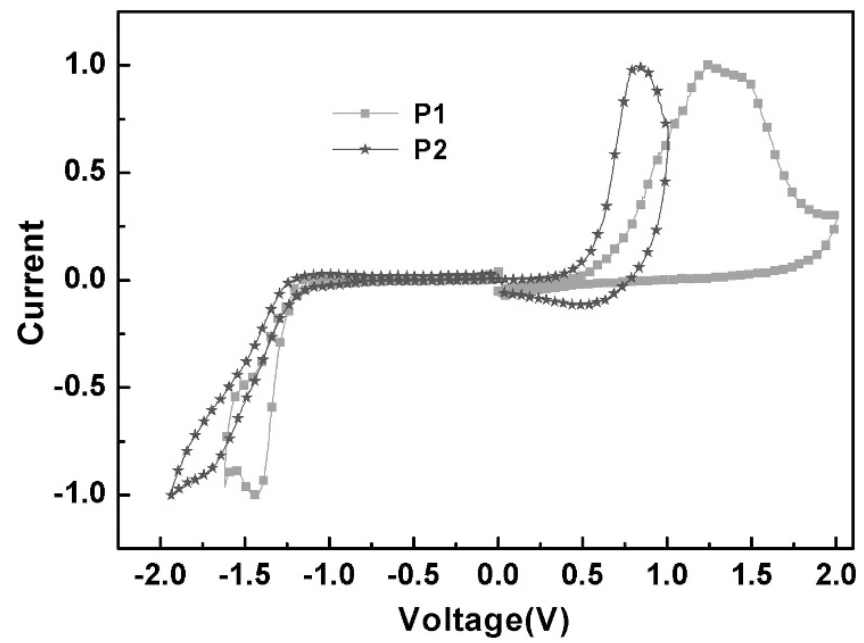

Figure 3 Electrochemical properties of the polymers. A full color version of this figure is available at Polymer Journal online.

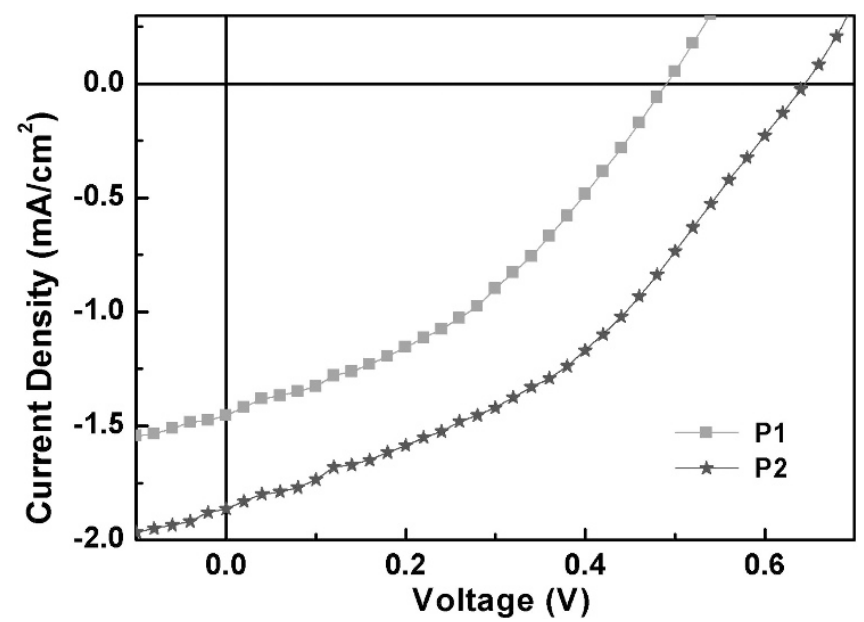

Figure 4 Current density-potential characteristics of the polymer solar cells under the illumination of AM 1.5, $100 \mathrm{~mW} \mathrm{~cm}^{-2}$. A full color version of this figure is available at Polymer Journal online.

Table 3 Electrochemical potentials and energy levels of the polymers

\begin{tabular}{|c|c|c|c|c|c|c|}
\hline Polymers & $\begin{array}{l}\text { Optical band } \\
\text { gapa (ev) }\end{array}$ & $\begin{array}{l}\mathrm{HOMO}^{\mathrm{b}} \\
(\mathrm{eV})\end{array}$ & $\begin{array}{l}\text { LUMOC } \\
(\mathrm{eV})\end{array}$ & $\begin{array}{l}\mathrm{E}_{\text {oxd }} \\
(V)\end{array}$ & $\begin{array}{l}\mathrm{E}_{\text {red }}^{\mathrm{d}} \\
(\mathrm{V})\end{array}$ & $\begin{array}{l}\text { Electrochemical } \\
\text { band gap }(\mathrm{eV})\end{array}$ \\
\hline P1 & 1.55 & -5.39 & -3.56 & 0.59 & -1.24 & 1.83 \\
\hline P2 & 1.53 & -5.36 & -3.60 & 0.56 & -1.20 & 1.76 \\
\hline
\end{tabular}

Abbreviations: CV, cyclic voltammetry; HOMO, highest occupied molecular orbital; LUMO, lowest unoccupied molecular orbital.

aptical energy band gap was estimated from the onset wavelength of the optical absorption. bCalculated from the oxidation potentials.

cCalculated from the reduction potentials.

${ }^{d}$ Onset oxidation and reduction potential measured by $\mathrm{CV}$.

${ }^{e}$ Calculated from the $E_{0 x}$ and $E_{\text {red }}$.

characteristics of devices with the configuration of ITO/PEDOT:PSS $(40 \mathrm{~nm}) /$ polymer: $\mathrm{PC}_{71} \mathrm{BM}(1: 3 ; 80 \mathrm{~nm}) / \mathrm{Al}(100 \mathrm{~nm})$ under $\mathrm{AM} 1.5 \mathrm{G}$ irradiation $\left(100 \mathrm{~mW} \mathrm{~cm}^{-2}\right)$ are depicted in Figure 4 . The photovoltaic parameters of all of the polymers, including the $V_{\mathrm{OC}}, J_{\mathrm{SC}}$, fill factor $(F F)$ and PCE, are summarized in Table 4. The device comprised of $\mathbf{P 1}$ had a $V_{\mathrm{OC}}$ value of $0.48 \mathrm{~V}$, a $J_{\mathrm{SC}}$ value of $1.43 \mathrm{~mA} \mathrm{~cm}^{-2}$ and an FF value of 0.38 , yielding a PCE of $0.26 \%$. The device with P2:PC ${ }_{71} \mathrm{BM}$ had a $V_{\mathrm{OC}}$ value of $0.65 \mathrm{~V}$, a $J_{\mathrm{SC}}$ value of 
Table 4 Photovoltaic properties of the polymer solar cells

\begin{tabular}{lcccc}
\hline Polymers & $\mathrm{V}_{O C}(\mathrm{~V})$ & $\mathrm{J}_{S C}\left(\mathrm{mAcm}^{-2}\right)$ & $F F$ & $P C E(\%)$ \\
\hline P1 & 0.48 & 1.43 & 0.38 & 0.26 \\
P2 & 0.65 & 1.86 & 0.39 & 0.47 \\
\hline
\end{tabular}

Abbreviations: $J_{\mathrm{SC}}$, short circuit current density; PCE, power conversion efficiency; $V_{\mathrm{OC}}$, open circuit voltage.

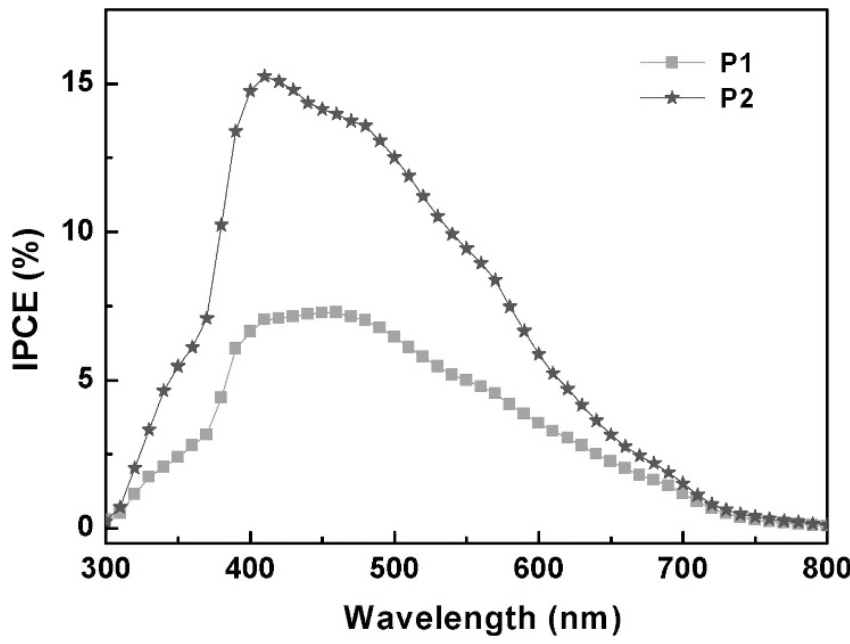

Figure 5 Incident photon-to-current efficiency (IPCE) curves of the polymer:PCBM (1:2) under the illumination of AM $1.5,100 \mathrm{~mW} \mathrm{~cm}^{-2}$. A full color version of this figure is available at Polymer Journal online.

$1.86 \mathrm{~mA} \mathrm{~cm}^{-2}$ and an $F F$ value of 0.39 , resulting in a PCE of $0.47 \%$, which is higher than that of $\mathbf{P} \mathbf{1}$ due to the higher solubility achieved with the ethylhexyl chain. Generally, conjugated polymers with a branched side chain exhibit relatively narrow absorption, large bandgaps, low mobility and poor photovoltaic properties. However, in this work, the P1 polymer with a linear alkyl side chain has poor photovoltaic properties because P1 has a lower $M_{\mathrm{w}}$ due to its lower solubility. The incident photon-to-current efficiency spectra of the photovoltaic devices composed of polymer: $\mathrm{PC}_{71} \mathrm{BM}$ blends are presented in Figure 5. The incident photon-to-current efficiency spectrum of $\mathbf{P} 2$ shows a maximum of $15.3 \%$ at $410 \mathrm{~nm}$.

\section{CONCLUSIONS}

Alternating copolymers with an electron-rich dialkoxybenzo[1,2$\left.b: 3,4-b^{\prime}\right]$ dithiophene unit and an electron-deficient dimethylbenzimidazole unit have been synthesized via the Stille polymerization reaction. The solid films of $\mathbf{P 1}$ and $\mathbf{P} 2$ showed absorption bands with maximum peaks at $\sim 449,633$ and 434 and $636 \mathrm{~nm}$ and absorption onsets at 799 and $810 \mathrm{~nm}$, corresponding to bandgaps of 1.55 and $1.53 \mathrm{eV}$, respectively. The oxidation onsets of $\mathbf{P} 1$ and $\mathbf{P} 2$ were estimated to be 0.36 and $0.56 \mathrm{~V}$, which correspond to HOMO energy levels of -5.16 and $-5.37 \mathrm{eV}$, respectively. The device with P2: $\mathrm{PC}_{71} \mathrm{BM}$ had a $V_{\mathrm{OC}}$ value of $0.65 \mathrm{~V}$, a $J_{\mathrm{SC}}$ value of $1.86 \mathrm{~mA} \mathrm{~cm}^{-2}$ and an $F F$ value of 0.39 , yielding a PCE of $0.47 \%$.

\section{ACKNOWLEDGEMENTS}

This work was supported by a National Research Foundation of Korea (NRF) grant funded by the Korean government (Ministry of Education, Science and
Technology (MEST; no. 2010-0015069) and by the Basic Science Research Program through the NRF), and funded by the MEST (no. 2011-0010851).

1 Cheng, Y. J., Wu, J. S., Shih, P., Chang, C. Y., Jwo, P. C., Kao, W. S. \& Hsu, C. S. Carbazole-based ladder-type heptacylic arene with aliphatic side chains leading to enhanced efficiency of organic photovoltaics. Chem. Mater. 23, 2361-2369 (2011).

2 Shen, X., Chen, S., Xiao, Z., Zuo, Q., Chen, Y. \& Ding, L. Synthesis of thienoselenadiazolecontaining conjugated copolymers and their application in polymer solar cells. Polym. J. 44, 978-981 (2012).

3 Aernouts, T., Aleksandrov, T., Girotto, C., Genoe, J. \& Poortmans, J. Polymer based organic solar cells using ink-jet printed active layers. Appl. Phys. Lett. 92, 033306/1033306/3 (2008)

4 Kim, S. S., Na, S. I., Kang, S. J. \& Kim, D. Y. Annealing-free fabrication of P3HT:PCBM solar cells via simple brush painting. Sol. Energ. Mat. Sol. C 94, 171-175 (2010).

5 Krebs, F. C., Gevorgyan, S. A. \& Alstrup, J. A roll-to-roll process to flexible polymer solar cells: model studies, manufacture and operational stability studies. J. Mater. Chem. 19, 5442-5451 (2009).

6 Yu, G., Gao, J., Hummelen, J. C., Wudl, F. \& Heeger, A. J. Polymer photovoltaic cells: enhanced efficiencies via a network of internal donor-acceptor heterojunctions. Science 270, 1789-1791 (1995).

7 Lin, L. Y., Chen, Y. H., Huang, Z. Y., Lin, H. W., Chou, S. H., Lin, F., Chen, C. W., Liu, Y. H. \& Wong, K. T. A low-energy-gap organic dye for high-performance small-molecule organic solar cells. J. Am. Chem. Soc. 133, 15822-15825 (2011).

8 Mikroyannidis, J. A., Stylianakis, M. M., Suresh, P., Balraju, P. \& Sharma, G. D. Low band gap vinylene compounds with triphenylamine and benzothiadiazole segments for use in photovoltaic cells. Org. Electron 10, 1320-1333 (2009).

9 Mikroyannidis, J. A., Suresh, P. \& Sharma, G. D. Synthesis of benzoselenadiazolebased small molecule and phenylenevinylene copolymer and their application for efficient bulk heterojunction solar cells. Org. Electron 11, 311-321 (2010).

$10 \mathrm{Li}$, Y. \& Zou, Y. Conjugated polymer photovoltaic materials with broad absorption band and high charge carrier mobility. Adv. Mater. 20, 2952-2958 (2008).

11 Wang, E., Wang, L., Lan, L., Luo, C., Zhuang, W., Peng, J. \& Cao, Y. High-performance polymer heterojunction solar cells of a polysilafluorene derivative. Appl. Phys. Lett. 92, 033307/1-033307/3 (2008)

12 Karikomi, M., Kitamura, C., Ranaka, S. \& Yamashita, Y. New narrow-bandgap polymer composed of benzobis(I,2,5-thiadiazole) and thiophenes. J. Am. Chem. Soc. 117, 6791-6792 (1995).

13 Song, S., Jin, Y., Park, S. H., Cho, S., Kim, I., Lee, K., Heeger, A. J. \& Suh, H. A lowbandgap alternating copolymer containing the dimethyl-2 $\mathrm{H}$-benzimidazole moiety. J. Mater. Chem. 20, 6517-6523 (2010)

14 Song, S., Park, S. H., Jin, Y, Park, J., Shim, J. Y, Kim, L., Lee, H., Lee, K. \& Suh, H. Synthesis and characterization of low-bandgap copolymers based on dihexyl$2 \mathrm{H}$-benzimidazole and cyclopentadithiophene. J. Polym. Sci. Polym. Chem. 48, 4567-4573 (2010).

15 Park, S. H., Roy, A., Beaupre, S., Cho, S., Coates, N., Moon, J. S., Moses, D., Leclerc, M., Lee, K. \& Heeger, A. J. Bulk heterojunction solar cells with internal quantum efficiency approaching 100\%. Nat. Photonics 3, 297-302 (2009).

16 Liu, C. L., Tsai, J. H., Lee, W. Y., Chen, W. C. \& Jenekhe, S. A. New didecyloxyphenylene-acceptor alternating conjugated copolymers: synthesis, properties, and optoelectronic device applications. Macromolecules 41, 6952-6959 (2008).

17 Gadisa, A., Mammo, W., Andersson, L. M., Admassie, S., Zhang, F., Andersson, M. R. \& Inganäs, O. A new donor-acceptor-donor polyfluorene copolymer with balanced electron and hole mobility. Adv. Funct. Mater. 17, 3836-3842 (2007).

18 Song, S., Kim, C., Park, S. H., Kim, I., Lee, K., Jin, Y. \& Suh, H. Synthesis and characterization of polycyclopentaphenanthrene with carbazole or oxidiazole pendant units. Polym. J. 44, 347-352 (2012).

19 Jeeva, S., Lukoyanova, O., Karas, A., Dadvand, A., Rosei, F. \& Perepichka, D. F. Highly emissive and electrochemically stable thienylene vinylene oligomers and copolymers: an unusual effect of alkylsulfanyl substituents. Adv. Funct. Mater. 20, 1661-1669 (2010).

20 Liang, Y., Xu, Z., Xia, J., Tsai, S. T., Wu, Y., Li, G., Ray, C. \& Yu, L. For the bright futurebulk heterojunction polymer aolar cells with power conversion efficiency of $7.4 \%$. Adv. Mater. 22, E135-E138 (2010).

21 Wang, E., Wang, M., Wang, L., Duan, C., Zhang, J., Cai, W., He, C., Wu, H. \& Cao, Y. Donor polymers containing benzothiadiazole and four thiophene rings in their repeating units with improved photovoltaic performance. Macromolecules 42, 4410-4415 (2009).

22 Son, H. J., Wang, W., Xu, T., Liang, Y., Wu, Y., Li, G. \& Yu, L. Synthesis of fluorinated polythienothiophene-co-benzodithiophenes and effect of fluorination on the photovoltaic properties. J. Am. Chem. Soc. 133, 1885-1894 (2011).

23 Allard, N., Beaupre, S., Aich, B. R., Najari, A., Tao, Y. \& Leclerc, M. Synthesis and characterization of new poly(thieno[3,4-d]thiazole) derivatives for photovoltaic applications. Macromolecules 44, 7184-7187 (2011).

24 Kanimozhi, C., Balraju, P., Sharma, G. D. \& Patil, S. Synthesis of diketopyrrolopyrrole containing copolymers: a study of their optical and photovoltaic properties. J. Phys. Chem. B 114, 3095-3103 (2010).

25 Fang, Y. K., Liu, C. L., Yang, G. Y., Chen, P. C. \& Chen, W. C. New donor-acceptor random copolymers with pendent triphenylamine and 1,3,4-oxadiazole for highperformance memory device applications. Macromolecules 44, 2604-2612 (2011).

Supplementary Information accompanies the paper on Polymer Journal website (http://www.nature.com/pj) 